\title{
INVENTÁRIO DE PLANTAS FORNECEDORAS DE PRODUTOS NÃO MADEIREIROS DA FLORESTA OMBRÓFILA MISTA NO ESTADO DO PARANÁ
}

\section{INVENTORY OF PLANTS THAT PROVIDE NON-WOODY FOREST PRODUCTS IN A MIXED-ARAUCARIA FOREST IN PARANA STATE, BRAZIL}

\author{
Carlos Roberto SANQUETTA ${ }^{1}$ \\ Lucila de Almeida Vasques FERNANDES ${ }^{2}$ \\ Dirceu Lúcio Carneiro de MIRANDA ${ }^{3}$ \\ Francelo MOGNON ${ }^{4}$
}

\begin{abstract}
RESUMO
A Floresta Ombrófila Mista (FOM) foi intensamente explorada no passado, em parte devido à forte extração de madeira e lenha da floresta. Atualmente, a legislação ambiental restringe, e em muitos casos impede, o corte de madeira da floresta, tornando-a um problema para os proprietários rurais, que acabam por optar pela extração ilegal. $O$ objetivo do estudo foi identificar e quantificar as espécies florestais não madeireiras de um fragmento de FOM localizado em São João do Triunfo-PR. Foram inventariadas as espécies arbóreas e as espécies não arbóreas de hábito terrestre e epifítico. Para inventário das espécies arbóreas foram utilizadas 350 parcelas de $100 \mathrm{~m}^{2}$ e das espécies não arbóreas foram utilizadas 128 parcelas de $4 \mathrm{~m}^{2}$. Foi realizada a análise fitossociológica e uma revisão de literatura com o propósito de verificar os potenciais usos não madeireiros das espécies inventariadas. Os resultados apontaram a presença de 884 indivíduos arbóreos por ha, pertencentes a 71 espécies. Destas, 62\% apresentaram possíveis usos não madeireiros. Quanto aos indivíduos não arbóreos, o inventário revelou 15.371 indivíduos ha ${ }^{-1}$ com hábito terrestre e 4.063 epífitas por ha, pertencentes a 63 espécies, sendo que $44 \%$ podem fornecer produtos florestais não madeireiros (PFNM). Pode-se concluir que o fragmento estudado possui uma grande quantidade de espécies e estas podem fornecer múltiplos usos para os proprietários rurais.

Palavras chaves: Espécies não madeireiras; manejo sustentável; análise fitossociológica.
\end{abstract}

\begin{abstract}
The Araucaria Forest was intensively exploited in the past, in the part for timber and firewood extraction from the forest. Currently environmental legislation restricts and in many cases prohibits the cutting of forest wood, making it often a problem for landowners who eventually chose illegal extraction. The study objective was to identify and quantify the non-wood forests species of a fragment of Araucaria Forest. The study was carried out in a fragment of Araucaria Forest in São João do Triunfo, Brazil, where the species with terrestrial and epiphytic habit were taken into account. The inventory of the tree species was conducted through the use of 350 plots of $100 \mathrm{~m}^{2}$ and the inventory of other species was conducted through the use of 128 plots of $4 \mathrm{~m}^{2}$. The phytosociological analysis was performed and a review of literature was performed with the purpose of verifying the potential uses of non-wood forests species surveyed. The results indicated the presence of 884 trees.ha ${ }^{-1}$, with the identification of 71 species. Of these, $61.97 \%$ had possible non-wood uses. As those not trees, the inventory showed 15,371 individuals ha $^{-1}$ with terrestrial habit and 4,063 epiphytes per ha, with the identification of 63 species, of which $44.44 \%$ can provide non-wood forests products. It can be concluded that the fragment studied had a large number of species and these can provide multiple uses for landowners, minimizing the illegal exploitation of wood, may be an economically viable alternative, environmentally correct, directing the property to the sustainable management.
\end{abstract}

Key-words: Non-wood forests species; sustainable management; phytosociological analysis.

\footnotetext{
${ }^{1}$ Engenheiro Florestal, Ph.D., UFPR, Professor, Curitiba, PR, Brasil. E-mail: sanquetta@ufpr.br. Autor para corespondência.

${ }^{2}$ Engenheira Florestal, Silviconsult Consultoria, Mestre em Manejo Florestal, Curitiba, PR, Brasil. E-mail: lucilavf@yahoo.com.br.

Endereço para correspondência: Av. Prefeito Lothário Meissner, 632, Jardim Botânico, CEP 80.210-170 - Curitiba / PR / Brasil, Campus III UFPR, Prédio de Ciências Florestais e da Madeira, Laboratório de Inventário Florestal.

${ }^{3}$ Engenheiro Florestal, M.Sc., UFMT, Professor, Sinop, MT, Brasil. E-mail: mirandaufpr@yahoo.com.br

${ }^{4}$ Biólogo, Mestrando em Manejo Florestal, UFPR, Aluno do Curso de Pós-Graduação, Curitiba, PR, Brasil. E-mail: ocelobio@yahoo.com.br
} 
SANQUETTA, C. R. et al. Inventário de plantas fornecedoras..

\section{INTRODUÇÃO}

As florestas fornecem uma variada gama de produtos, tanto madeireiros como não madeireiros. Contudo, a maior parte dos estudos e pesquisas é voltada para os produtos provenientes da madeira. Atualmente, o interesse em nos produtos florestais não madeireiros (PFNM) vêm aumentado, pois o valor madeireiro das florestas vem diminuindo devido à redução de sua área, particularmente na Floresta Ombrófila Mista (FOM), que atualmente apresenta, no estado do Paraná, apenas cerca de $0,8 \%$ da sua área com remanescentes primários (FUPEF, 2004).

Aspectos sociais, econômicos e ambientais são decisivos no contexto dos PFNM, pois a sua utilização pode representar uma nova forma de geração de renda, pois hoje é proibido por lei o corte de muitas espécies vegetais (Lei Federal 11.428/2006 e Resolução CONAMA 278/2001), desestimulando o uso madeireiro (Sanquetta \& Mattei, 2006).

Conforme Balzon et al. (2004), a atividade de extração de PFNM tem que buscar o equilíbrio entre a produção econômica e a conservação da floresta, mediante a melhoria da qualidade geral das operações de extração, preservando e conservando os recursos naturais e ao mesmo tempo mantendo trabalho e renda aos extrativistas. Santos et al. (2003) acrescentam que o desafio em transformar muitos desses produtos em alternativas comerciais, sociais e ecológicas viáveis, é a correta quantificação e projeção do seu valor.

Há poucos trabalhos sobre a identificação e quantificação de PFNM. Alguns exemplos são os estudos realizados por Wickens (1991), Moraes et al. (2006), Pedroso et al. (2007), Blum \& Oliveira (2006), Guerra et al. (2009). Assim, este estudo tem o intuito de identificar as possíveis espécies vegetais fornecedoras de produtos florestais não madeireiros de um fragmento de Floresta Ombrófila Mista, assim como analisar a sua abundância florística e sua distribuição espacial, servindo como informação base para futuros trabalhos relacionados ao manejo sustentável da Floresta Ombrófila Mista.

\section{MATERIAL E MÉTODOS}

O presente estudo consistiu em um inventário das espécies vegetais arbóreas e não arbóreas na Estação Experimental da Universidade Federal do Paraná em São João do Triunfo - PR e em uma revisão de literatura para verificação das potenciais espécies vegetais fornecedoras de PFNM, bem como na quantificação destas por meio de análise fitossociológica.

\section{Descrição da área de estudo}

A Estação Experimental em São João do Triunfo - PR é integrante do PELD - Site 9 do $\mathrm{CNPq}$ (Programa de Pesquisas Ecológicas de Longa Duração - Site 9 relativo à Floresta com Araucária e suas Transições, do Conselho Nacional de Desenvolvimento Científico e Tecnológico) e de propriedade da Universidade Federal do Paraná. Apresenta cerca de 32 ha e está localizada no município de São João do Triunfo, na Região Centro-Sul do Paraná, a uma distância de aproximadamente $125 \mathrm{~km}$ de Curitiba. A altitude do local é de $780 \mathrm{~m}$ e as coordenadas são $25^{\circ} 34^{\prime} 18^{\prime \prime}$ latitude Sul e $50^{\circ} 05^{\prime} 56^{\prime \prime}$ longitude Oeste. Segundo a classificação de Köppen, o clima da região é do tipo $\mathrm{Cfb}$ - clima temperado sempre úmido com temperatura média inferior a $22^{\circ} \mathrm{C}$ durante o mês mais quente, sem estação seca, com verões frescos e mais de cinco geadas noturnas por ano (Pizatto, 1999). A vegetação do local é caracterizada como um fragmento da Floresta Ombrófila Mista, bioma Mata Atlântica em estágio avançado de regeneração pelos parâmetros da Resolução CONAMA 02/94.

Existem na área quatro parcelas permanentes que foram instaladas conforme as diferenças fisionômicas da vegetação arbórea, de modo que fossem incluídas as diferentes características florestais da área, de topografia e de condições de sítio. As parcelas receberam os seguintes nomes: Imbuia, Araucária, Fogo e Rio. Estas parcelas são anualmente monitoradas por meio de inventário florestal contínuo desde 1995. As parcelas são quadradas, com 1 ha cada, com exceção de uma que possui forma irregular devido à presença do rio denominado Bromado e possui área de 0,5 ha. As parcelas são divididas em subparcelas de $10 \mathrm{~m} \times 10 \mathrm{~m}$, com os limites marcados com cano de PVC, totalizando assim 350 parcelas de $100 \mathrm{~m}^{2}$.

\section{Método de amostragem da vegetação}

Os dados das espécies arbóreas foram obtidos do inventário florestal contínuo realizado em 2006, quando foram identificadas e mensuradas todas as árvores que apresentavam diâmetro à altura do peito (DAP) acima de $10 \mathrm{~cm}$.

Para levantamento das espécies não arbóreas foram instaladas sub-sub-parcelas de $4 \mathrm{~m}^{2}$ distribuídas uniformemente nas sub-parcelas de $100 \mathrm{~m}^{2}$. Foram sorteadas 18 sub-parcelas em cada uma das três parcelas permanentes de 1 ha e mais 10 sub-parcelas na parcela permanente de 0,5 ha. Em cada sub-parcela sorteada foram instaladas duas sub-sub-parcelas em seus vértices, totalizando 128 sub-sub-parcelas.

Em cada sub-sub-parcela foram levantados todos os indivíduos de hábito terrestre, obtendo seus valores de área de cobertura (comprimento x largura de copa), assim como foram avaliadas as epífitas quanto à presença ou ausência nos forófitos contidos dentro das microparcelas, conforme metodologia proposta por Bittencourt et al. (2004). No levantamento das epífitas foram observados os indivíduos presentes até $8 \mathrm{~m}$ de altura no forófito, bem como foram anotados os estratos em que eles se encontravam $(0-1 \mathrm{~m} ; 1-2 \mathrm{~m} ; 2-4 \mathrm{~m} ; 4-6 \mathrm{~m} ; 6-8 \mathrm{~m})$. Todas as espécies encontradas no levantamento foram coletadas, secadas em estufa e herborizadas conforme os critérios especificados por IBGE 
(1992), para posterior identificação no museu botânico Gert Hatschbach, em Curitiba - PR.

Após a identificação das espécies foi realizada uma revisão de literatura, com base em vários livros e artigos científicos correlatos (Lorenzi, 1998; Carvalho, 2003; Lorenzi \& Matos, 2002; Sanquetta \& Mattei, 2006; Pedroso et al., 2007; Fenner et al., 2006) e websites (Moraes et al., 2006; Blum \& Oliveira, 2006; entre outros), sobre as espécies vegetais encontradas no inventário florestal, avaliando a possibilidade de fornecimento de produtos florestais não madeireiros, identificando assim, as espécies florestais não madeireiras e os respectivos usos e produtos fornecidos. Os usos não madeireiros fornecidos por estas espécies foram divididos em categorias: ornamentais/ paisagísticos, medicinais, potencial apícola, alimentícios/condimentares, tanino, resina, óleos e outros usos (utilizados nas indústrias farmacêutica, alimentícia, de cosméticos, produção de tintas e vernizes, utilização em curtumes, fabricação de produtos químicos, uso dos resíduos como adubo, forragem, insumos para indústrias em geral, confecção de artesanatos, etc.). Posteriormente, foi realizada a análise fitossociológica por meio do sistema FLOREXEL (Arce, 2002), a fim de analisar a distribuição espacial das espécies que compõem a comunidade, por meio dos parâmetros utilizados para expressá-la: densidade, dominância e frequência.

Para avaliação dos parâmetros da estrutura horizontal fornecida no levantamento fitossociológico, foram consideradas somente as espécies com uso não madeireiro que seguiram um ordenamento, conforme os seguintes fatores: a) variedade de usos não madeireiros (categorias de usos); b) quantidade de produtos fornecidos em cada categoria; c) com maiores citações em estudos.

\section{RESULTADOS E DISCUSSÂO}

\section{Inventário florestal das espécies arbóreas}

A partir dos resultados do inventário foi constatada a presença de 884 indivíduos arbóreos por ha, sendo identificadas 71 espécies. Por meio da revisão de literatura realizada, conforme descrito no item anterior, e com base nas espécies encontradas no inventário, foram registradas neste levantamento 44 espécies, pertencentes a 30 famílias botânicas, com potencial para uso não madeireiro, o que representa $62 \%$ do total de espécies. Este resultado é semelhante ao encontrado por Pedroso et al. (2007), que encontraram 49 espécies pertencentes a 27 famílias botânicas, em um estudo que objetivou analisar e descrever as espécies arbóreas com propriedades fitoterápicas ocorrentes em um fragmento de Floresta Ombrófila Mista em Irati - PR. No entanto, em um estudo realizado por Moraes et al. (2006) para avaliar o potencial não madeireiro das espécies arbóreas da Floresta Nacional de Irati $\mathrm{PR}$, foram encontradas 87 espécies fornecedoras de PFNM. Com relação às categorias de PFNM, foram verificadas 41 espécies com propriedades ornamentais para paisagismo e arborização urbana, 32 espécies medicinais, 19 com potencial apícola, 14 alimentícias/condimentares e 14 apresentam outros usos. Ainda foram verificadas 16 espécies fornecedoras de tanino, 5 de resinas e 5 de óleos. É importante ressaltar que foi verificada a existência de mais de um uso não madeireiro em várias espécies.

As espécies arbóreas mais representativas em relação à quantidade e variedade de PFNM fornecidos e encontrados na literatura foram: Schinus terebinthifolius Raddi, Ilex paraguariensis St. Hill., Araucaria angustifolia (Bert.) O. Kuntze, Maytenus ilicifolia Mart.ex. Reiss., Cedrela fissilis Vell., Inga sp., Mimosa scabrella Benth., Myrsine ferruginea (Ruiz \& Pav.) Mez, Eugenia involucrata DC., Eugenia uniflora L. e Luehea divaricata Mart. Essas espécies são citadas no presente estudo como "prioritárias", por se destacarem no que diz respeito ao fornecimento de PFNM.

Schinus terebinthifolius (aroeira) tem sido empregada com fins medicinais e religiosos (Azevedo \& Silva, 2006; Agra et al., 2007)), mas atualmente tem sido muito comercializada como condimento (Cardoso, 2008), conhecida como pimenta rosa. Ilex paraguariensis (erva-mate) é tradicionalmente usada para fabrico de chá e ervamate para chimarrão (Storck et al., 2002). Já o grande valor de Araucaria angustifolia (araucária) em termos de PFNM é a sua semente, o pinhão (Amarante et al., 2007) - usada para diversos fins culinários - embora a espécie apresente muitos outros usos. Maytenus Ilicifolia (espinheira-santa), por sua vez, tem reconhecidamente grande valor medicinal. Cedela fissilis (cedro), Luehea divaricata (açoita-cavalo) e Myrsine ferruguinea (capororoca) também têm registro de uso medicinal (Backes \& Irgang, 2002; Fenner et al., 2006; Gazoni, 2009), enquanto Eugenia involucrata (cerejeira), Eugenia uniflora (pitanga) e Inga sp. (ingá) são bastante empregadas como alimento in natura ou em preparo de geleias, doces, etc., embora tenham também registro de uso para fins cosméticos e medicinais (Prado, 2009; Fiuza et al., 2008). Mimosa scabrella (bracatinga) têm usos não madeireiros variados, mas um grande valor dessa espécie é por ser melífera (Pegoraro \& Ziller, 2003).

A Tabela 1 mostra todas as espécies potencialmente fornecedoras de PFNM com seus respectivos usos, evidenciando as espécies prioritárias. 
SANQUETTA, C. R. et al. Inventário de plantas fornecedoras..

TABELA 1 - Lista de espécies arbóreas potenciais fornecedoras de PFNM do fragmento de Floresta Ombrófila Mista localizado em São João do Triunfo - PR.

\begin{tabular}{|c|c|}
\hline $\begin{array}{l}\text { FAMÍLIA } \\
\text { ESPÉCIE }\end{array}$ & USOS \\
\hline $\begin{array}{l}\text { Anacardiaceae } \\
\text { Lithraea brasiliensis March. }\end{array}$ & $\begin{array}{l}\text { Medicinal; ornamental/paisagismo; fabricação de tintas } \\
\text { para tecidos }\end{array}$ \\
\hline $\begin{array}{l}\text { Anacardiaceae } \\
\text { Schinus terebinthifolius Raddi * }\end{array}$ & $\begin{array}{l}\text { Medicinal; alimentício; ornamental/paisagismo; potencial } \\
\text { apícola; fabricação de tintas e vernizes, utilizada em } \\
\text { curtumes, outros usos }\end{array}$ \\
\hline $\begin{array}{l}\text { Annonaceae } \\
\text { Annona cacans Warm. }\end{array}$ & Medicinal; alimentício; ornamental/paisagismo \\
\hline $\begin{array}{l}\text { Aquifoliaceae } \\
\text { llex brevicuspis Reissek }\end{array}$ & Ornamental/paisagismo \\
\hline $\begin{array}{l}\text { Aquifoliaceae } \\
\text { llex dumosa Reissek }\end{array}$ & Ornamental/paisagismo \\
\hline $\begin{array}{l}\text { Aquifoliaceae } \\
\text { Ilex paraguariensis St. Hill. * }\end{array}$ & $\begin{array}{lccc}\text { Medicinal; } & \text { alimentício; } & \text { cosmético; } & \text { ornamental/ } \\
\text { paisagismo; outros usos }\end{array}$ \\
\hline $\begin{array}{l}\text { Araucariaceae } \\
\text { Araucaria angustifolia (Bert.) Kuntze * }\end{array}$ & $\begin{array}{l}\text { Medicinal; alimentício; artesanal; ornamental/paisagismo; } \\
\text { fabricação de tintas e vernizes; outros usos }\end{array}$ \\
\hline $\begin{array}{l}\text { Asteraceae } \\
\text { Gochnatia polymorpha (Less.) Cabrera }\end{array}$ & Medicinal; potencial apícola; ornamental/paisagismo \\
\hline $\begin{array}{l}\text { Asteraceae } \\
\text { Piptocarpha angustifolia Dusén }\end{array}$ & Potencial apícola; ornamental/paisagismo \\
\hline $\begin{array}{l}\text { Asteraceae } \\
\text { Vernonia discolor (Spreng.) Less. }\end{array}$ & Potencial apícola; ornamental/paisagismo \\
\hline $\begin{array}{l}\text { Bignoniaceae } \\
\text { Jacaranda puberula Cham. }\end{array}$ & Medicinal; ornamental/paisagismo \\
\hline $\begin{array}{l}\text { Canellaceae } \\
\text { Capsicodendron dinisii (Schwacke) Occhioni }\end{array}$ & Medicinal; ornamental/paisagismo \\
\hline $\begin{array}{l}\text { Celastraceae } \\
\text { Maytenus ilicifolia Mart.ex. Reiss. * }\end{array}$ & Medicinal; ornamental/paisagismo \\
\hline $\begin{array}{l}\text { Euphorbiaceae } \\
\text { Sapium glandulatum (Vell.) Pax }\end{array}$ & Medicinal; ornamental/paisagismo \\
\hline $\begin{array}{l}\text { Euphorbiaceae } \\
\text { Sebastiana commersoniana (Baill.) Smith \& Downs }\end{array}$ & Potencial apícola; ornamental/paisagismo \\
\hline $\begin{array}{l}\text { Flacourtiaceae } \\
\text { Casearia decandra Jacq. }\end{array}$ & Medicinal; ornamental/paisagismo \\
\hline $\begin{array}{l}\text { Lauraceae } \\
\text { Nectandra megapotamica (Spreng.) Mez }\end{array}$ & Medicinal; ornamental/paisagismo \\
\hline $\begin{array}{l}\text { Lauraceae } \\
\text { Ocotea porosa (Nees) L. Barroso Barr. }\end{array}$ & Cosmético; potencial apícola; ornamental/paisagismo \\
\hline $\begin{array}{l}\text { Lauraceae } \\
\text { Ocotea puberula (Rich.) Nees }\end{array}$ & Medicinal; ornamental/paisagismo; outros usos \\
\hline $\begin{array}{l}\text { Lauraceae } \\
\text { Persia major (Nees) Kopp }\end{array}$ & Medicinal \\
\hline $\begin{array}{l}\text { Meliaceae } \\
\text { Cedrela fissilis Vell. * }\end{array}$ & $\begin{array}{l}\text { Medicinal; potencial apícola; ornamental/paisagismo; } \\
\text { outros usos }\end{array}$ \\
\hline $\begin{array}{l}\text { Mimosaceae } \\
\text { Albizia polycephala (Benth.) Killip ex Record }\end{array}$ & Medicinal; alimentício; potencial apícola \\
\hline $\begin{array}{l}\text { Mimosaceae } \\
\text { Inga sp. * }\end{array}$ & $\begin{array}{l}\text { Medicinal; alimentício; potencial apícola; ornamental/ } \\
\text { paisagismo; utilizada em curtumes; outros usos }\end{array}$ \\
\hline $\begin{array}{l}\text { Mimosaceae } \\
\text { Mimosa scabrella Benth. * }\end{array}$ & $\begin{array}{l}\text { Medicinal; cosmético; potencial apícola; ornamental/ } \\
\text { paisagismo; outros usos }\end{array}$ \\
\hline $\begin{array}{l}\text { Myrsinaceae } \\
\text { Myrsine ferruginea (Ruiz \& Pav.) Mez * }\end{array}$ & $\begin{array}{l}\text { Medicinal; alimentício; potencial apícola; ornamental/ } \\
\text { paisagismo; outros usos }\end{array}$ \\
\hline $\begin{array}{l}\text { Myrsinaceae } \\
\text { Myrsine umbellata Mart. }\end{array}$ & Medicinal; ornamental/paisagismo; outros usos \\
\hline
\end{tabular}


SANQUETTA, C. R. et al. Inventário de plantas fornecedoras...

\begin{tabular}{|c|c|}
\hline $\begin{array}{l}\text { Myrtaceae } \\
\text { Campomanesia guazumifolia (Cam.) Berg }\end{array}$ & Medicinal; alimentício; ornamental/paisagismo \\
\hline $\begin{array}{l}\text { Myrtaceae } \\
\text { Campomanesia xanthocarpa Berg. }\end{array}$ & $\begin{array}{l}\text { Medicinal; alimentício; potencial apícola; ornamental/ } \\
\text { paisagismo; outros usos }\end{array}$ \\
\hline $\begin{array}{l}\text { Myrtaceae } \\
\text { Eugenia involucrata DC. * }\end{array}$ & Medicinal; alimentício; ornamental/paisagismo \\
\hline $\begin{array}{l}\text { Myrtaceae } \\
\text { Eugenia uniflora L. }{ }^{*}\end{array}$ & Medicinal; alimentício; ornamental/paisagismo \\
\hline $\begin{array}{l}\text { Myrtaceae } \\
\text { Myrcia glabra (O. Berg) D. Legrand }\end{array}$ & Ornamental/paisagismo \\
\hline $\begin{array}{l}\text { Myrtaceae } \\
\text { Myrcia rostrata DC. }\end{array}$ & Ornamental/paisagismo \\
\hline $\begin{array}{l}\text { Myrtaceae } \\
\text { Psidium cattleianum Sabine }\end{array}$ & $\begin{array}{l}\text { Medicinal; alimentício; ornamental/paisagismo; outros } \\
\text { usos }\end{array}$ \\
\hline $\begin{array}{l}\text { Palmae } \\
\text { Syagrus romanzofianum (Cham.) Glassm. }\end{array}$ & Potencial apícola; ornamental/paisagismo \\
\hline $\begin{array}{l}\text { Proteaceae } \\
\text { Roupala brasiliensis Klotz. }\end{array}$ & Ornamental/paisagismo \\
\hline $\begin{array}{l}\text { Rosaceae } \\
\text { Prunus brasiliensis (Cham. \& Schlecht.) D. }\end{array}$ & Medicinal \\
\hline $\begin{array}{l}\text { Rutaceae } \\
\text { Zanthoxylum rhoifolium Lam. }\end{array}$ & Medicinal; potencial apícola; ornamental/paisagismo. \\
\hline $\begin{array}{l}\text { Sapindaceae } \\
\text { Allophylus edulis (St. Hil.) Radlk. }\end{array}$ & $\begin{array}{l}\text { Medicinal; alimentício; potencial apícola; ornamental/ } \\
\text { paisagismo }\end{array}$ \\
\hline $\begin{array}{l}\text { Sapindaceae } \\
\text { Cupania vernalis Camb. }\end{array}$ & $\begin{array}{l}\text { Medicinal; potencial apícola; ornamental/paisagismo; } \\
\text { outros usos }\end{array}$ \\
\hline $\begin{array}{l}\text { Sapindaceae } \\
\text { Matayba elaeagnoides Radlk. }\end{array}$ & $\begin{array}{l}\text { Medicinal; potencial apícola; ornamental/paisagismo; } \\
\text { outros usos }\end{array}$ \\
\hline $\begin{array}{l}\text { Symplocaceae } \\
\text { Symplocos tetrandra Mart. }\end{array}$ & Ornamental/paisagismo \\
\hline $\begin{array}{l}\text { Tiliaceae } \\
\text { Luehea divaricata Mart. * }\end{array}$ & $\begin{array}{l}\text { Medicinal; potencial apícola; Ornamental/paisagismo; } \\
\text { utilizada em curtumes; outros usos }\end{array}$ \\
\hline $\begin{array}{l}\text { Verbenaceae } \\
\text { Vitex montevidensis Cham. }\end{array}$ & Alimentício; potencial apícola; ornamental/paisagismo \\
\hline $\begin{array}{l}\text { Winteraceae } \\
\text { Drimys brasiliensis Miers }\end{array}$ & Medicinal; ornamental/paisagismo \\
\hline
\end{tabular}

*Espécies arbóreas prioritárias

Entre as espécies prioritárias houve bastante diferença entre os valores de índice de valor de importância (IVI), com algumas apresentando valores mais altos, como Araucaria angustifolia e llex paraguariensis, com $75,76 \%$ e $12,48 \%$ respectivamente, ressaltando que a primeira foi a espécie que apresentou os maiores valores de densidade, dominância e frequência no inventário. Espécies como Inga sp. e Maytenus ilicifolia apresentaram os menores valores de IVI, com 0,41 e $0,18 \%$ respectivamente. As demais espécies prioritárias encontram-se entre valores intermediários de IVI.

Espécies como Myrsine ferruginea, Cedrela fissilis, Luehea divaricata, Mimosa scabrella e Schinus terebinthifolius mostraram valores de densidade absoluta de 25, 8, 4, 9 e 7 indivíduos $\mathrm{ha}^{-1}$, respectivamente, ou seja, apesar de oferecerem um bom número de PFNM, encontram- se em baixo número de indivíduos por hectare quando comparadas as outras espécies do inventário. O mesmo pode ser dito em relação a Eugenia uniflora e Eugenia involucrata, que apresentaram valores de densidade absoluta de 6 e 2 indivíduos ha ${ }^{-1}$ respectivamente.

As diferenças dos valores das variáveis estruturais horizontais entre as espécies do inventário podem ocorrer devido a vários motivos, como a biologia da espécie, grau de antropização, fase sucessional da floresta, etc. No caso específico das espécies deste estudo, atribui-se essas diferenças principalmente ao grau de antropização e às estratégias de dispersão das espécies.

As variáveis estruturais horizontais das espécies fornecedoras de PFNM podem ser verificadas na Tabela 2 , assim como podem ser analisados os valores de IVI das espécies prioritárias. 
SANQUETTA, C. R. et al. Inventário de plantas fornecedoras..

TABELA 2 - Variáveis estruturais horizontais das espécies arbóreas fornecedoras de PFNM em um fragmento de Floresta Ombrófila Mista localizado em São João do Triunfo - PR.

\begin{tabular}{|c|c|c|c|c|c|c|c|c|}
\hline & $\mathrm{DN} \mathrm{Ab}$ & $\mathrm{DAb}$ & $\mathrm{FR} \mathrm{Ab}$ & DN Rel & D Rel & FR Rel & IVC & IVI \\
\hline ESPÉCIE & Ind ha-1 & $\mathrm{m}^{2} \mathrm{ha}^{-1}$ & $\%$ & $\%$ & $\%$ & $\%$ & $\begin{array}{c}\% \\
0-200\end{array}$ & $\begin{array}{c}\% \\
0-300\end{array}$ \\
\hline Araucaria angustifolia * & 153,48 & 17,95 & 66,02 & 17,36 & 45,49 & 12,91 & 62,85 & 75,76 \\
\hline Matayba elaeagnoides & 39,28 & 2,35 & 22,56 & 4,44 & 5,95 & 4,41 & 10,39 & 14,81 \\
\hline Ilex paraguariensis * & 49,86 & 0,74 & 25,35 & 5,64 & 1,88 & 4,96 & 7,52 & 12,48 \\
\hline Ocotea porosa & 10,86 & 2,28 & 8,08 & 1,23 & 5,77 & 1,58 & 7,00 & 8,58 \\
\hline Ocotea puberula & 21,17 & 1,43 & 12,53 & 2,39 & 3,63 & 2,45 & 6,02 & 8,47 \\
\hline Capsicodendron dinisii & 26,74 & 0,85 & 13,93 & 3,02 & 2,14 & 2,72 & 5,17 & 7,89 \\
\hline Prunus brasiliensis & 21,73 & 0,60 & 15,60 & 2,46 & 1,51 & 3,05 & 3,97 & 7,02 \\
\hline Casearia decandra & 22,56 & 0,42 & 16,99 & 2,55 & 1,06 & 3,32 & 3,61 & 6,93 \\
\hline Campomanesia xanthocarpa & 20,89 & 0,77 & 13,09 & 2,36 & 1,95 & 2,56 & 4,31 & 6,87 \\
\hline Myrsine ferruginea * & 25,07 & 0,36 & 14,48 & 2,84 & 0,92 & 2,83 & 3,75 & 6,59 \\
\hline Lithraea brasiliensis & 21,73 & 0,53 & 12,81 & 2,46 & 1,34 & 2,51 & 3,79 & 6,30 \\
\hline Nectandra megapotamica & 11,70 & 0,80 & 8,36 & 1,32 & 2,04 & 1,63 & 3,36 & 5,00 \\
\hline Ilex dumosa & 13,37 & 0,05 & 9,19 & 1,51 & 0,14 & 1,80 & 1,65 & 3,45 \\
\hline Cedrela fissilis * & 7,80 & 0,39 & 6,96 & 0,88 & 1,00 & 1,36 & 1,88 & 3,24 \\
\hline Ilex brevicuspis & 8,91 & 0,23 & 7,24 & 1,01 & 0,58 & 1,42 & 1,59 & 3,00 \\
\hline Luehea divaricata * & 3,90 & 0,55 & 3,62 & 0,44 & 1,39 & 0,71 & 1,83 & 2,54 \\
\hline Cupania vernalis & 6,69 & 0,14 & 6,41 & 0,76 & 0,35 & 1,25 & 1,10 & 2,35 \\
\hline Sebastiana commersoniana & 8,64 & 0,17 & 4,46 & 0,98 & 0,42 & 0,87 & 1,40 & 2,27 \\
\hline Zanthoxylum rhoifolium & 7,52 & 0,11 & 5,57 & 0,85 & 0,29 & 1,09 & 1,14 & 2,23 \\
\hline Mimosa scabrella * & 9,47 & 0,05 & 4,18 & 1,07 & 0,12 & 0,82 & 1,19 & 2,01 \\
\hline Jacaranda puberula & 5,57 & 0,17 & 4,74 & 0,63 & 0,43 & 0,93 & 1,06 & 1,98 \\
\hline Sapium glandulatum & 5,29 & 0,10 & 5,29 & 0,60 & 0,26 & 1,03 & 0,86 & 1,89 \\
\hline Schinus terebinthifolius * & 7,24 & 0,03 & 5,01 & 0,82 & 0,07 & 0,98 & 0,89 & 1,87 \\
\hline Myrcia glabra & 6,69 & 0,09 & 4,46 & 0,76 & 0,23 & 0,87 & 0,99 & 1,86 \\
\hline Syagrus romanzofianum & 5,01 & 0,15 & 4,46 & 0,57 & 0,37 & 0,87 & 0,94 & 1,81 \\
\hline Eugenia uniflora * & 5,85 & 0,07 & 3,90 & 0,66 & 0,18 & 0,76 & 0,84 & 1,60 \\
\hline Gochnatia polymorpha & 4,74 & 0,08 & 3,62 & 0,54 & 0,20 & 0,71 & 0,74 & 1,44 \\
\hline Piptocarpha angustifolia & 3,62 & 0,10 & 3,06 & 0,41 & 0,24 & 0,60 & 0,65 & 1,25 \\
\hline Roupala brasiliensis & 3,06 & 0,05 & 2,79 & 0,35 & 0,12 & 0,54 & 0,47 & 1,01 \\
\hline Drimys brasiliensis & 3,06 & 0,03 & 2,51 & 0,35 & 0,08 & 0,49 & 0,42 & 0,91 \\
\hline Myrsine umbellata & 3,06 & 0,06 & 1,95 & 0,35 & 0,15 & 0,38 & 0,49 & 0,87 \\
\hline Eugenia involucrata * & 1,67 & 0,04 & 1,67 & 0,19 & 0,10 & 0,33 & 0,29 & 0,62 \\
\hline Persia major & 1,67 & 0,03 & 1,67 & 0,19 & 0,07 & 0,33 & 0,26 & 0,58 \\
\hline Inga sp. * & 1,11 & 0,03 & 1,11 & 0,13 & 0,07 & 0,22 & 0,19 & 0,41 \\
\hline Vernonia discolor & 1,11 & 0,01 & 1,11 & 0,13 & 0,03 & 0,22 & 0,16 & 0,38 \\
\hline Psidium cattleianum & 1,11 & 0,03 & 0,84 & 0,13 & 0,07 & 0,16 & 0,19 & 0,35 \\
\hline Campomanesia guazumifolia & 0,84 & 0,03 & 0,84 & 0,09 & 0,07 & 0,16 & 0,16 & 0,32 \\
\hline Annona cacans & 0,84 & 0,01 & 0,84 & 0,09 & 0,03 & 0,16 & 0,13 & 0,29 \\
\hline Allophylus edulis & 0,56 & 0,01 & 0,56 & 0,06 & 0,01 & 0,11 & 0,08 & 0,19 \\
\hline Symplocos tetrandra & 0,56 & 0,01 & 0,56 & 0,06 & 0,01 & 0,11 & 0,08 & 0,19 \\
\hline Maytenus ilicifolia * & 0,56 & 0,00 & 0,56 & 0,06 & 0,01 & 0,11 & 0,07 & 0,18 \\
\hline Vitex montevidensis & 0,28 & 0,02 & 0,28 & 0,03 & 0,04 & 0,05 & 0,07 & 0,13 \\
\hline Albizia polycephala & 0,28 & 0,00 & 0,28 & 0,03 & 0,01 & 0,05 & 0,04 & 0,09 \\
\hline Myrcia rostrata & 0,28 & 0,00 & 0,28 & 0,03 & 0,00 & 0,05 & 0,03 & 0,09 \\
\hline
\end{tabular}

DN: Densidade; D: Dominância absoluta; FR: Freqüência; IVC: Índice de valor de cobertura; IVI: Índice de valor de importância; Ab: Absoluta; Rel: Relativa.

* Espécies arbóreas prioritárias 
SANQUETTA, C. R. et al. Inventário de plantas fornecedoras...

\section{Inventário florestal das espécies não arbóreas}

Com relação aos indivíduos não arbóreos, o inventário apontou a presença de 15.371 indivíduos ha-1 com hábito terrestre e 4.063 indivíduos ha ${ }^{-1}$ com hábito epifítico, sendo possível a identificação de 50 e 13 espécies, respectivamente. A partir da revisão de literatura foram encontrados registros de 22 espécies com hábito terrestre, pertencentes a 17 famílias botânicas, que apresentam potenciais usos não madeireiros, ou seja, $42 \%$ de todas as espécies levantadas neste estudo.

Com relação às categorias de PFNM, foram verificadas 13 espécies com propriedades ornamentais para paisagismo e arborização urbana, 13 espécies medicinais, duas alimentícias/ condimentares, uma com potencial apícola e três apresentam outros usos. Ainda foram verificadas duas espécies produtoras de óleos e duas para produção de cosméticos, ressaltando que foi verificada a existência de mais de um uso não madeireiro em várias espécies.

No estudo com as espécies de hábito epifítico, foram encontrados registros de seis espécies, pertencentes a três famílias botânicas, que podem fornecer algum uso não madeireiro, ou seja, $46,15 \%$ das epífitas. Dentre estas espécies verificou-se o fornecimento apenas de produtos ornamentais e medicinais, sendo que todas as espécies apresentam propriedades ornamentais $\mathrm{e}$ duas medicinais.

Dentre as espécies de hábito terrestre destacam-se Macfadyena unguis-cati (L.) Gentry, Dicksonia sellowiana Hook., Piper xylosteoides (Kunth) Steud., Adiantum raddianum C. Presl e Brunfelsia pauciflora (Cham. \& Schltdl.) Benth., como as mais representativas em relação à quantidade de PFNM fornecidos e encontrados na literatura. Dentre as espécies de epífitas as mais representativas são Billbergia nutans Wendl., Aechmea recurvata (Klotzsch) L.B. Sm. e Campyloneurum phyllitidis (L.) Presl. Essas espécies também são citadas como "prioritárias", por se destacarem no que diz respeito ao fornecimneto de PFNM. As Tabelas 3 e 4 apresentam todas as espécies potenciais fornecedoras de PFNM com hábito terrestre $e$ epifítico, assim como seus respectivos usos, evideciando as espécies prioritárias.

TABELA 3 - Lista de espécies não arbóreas com hábito terrestre, potenciais fornecedoras de PFNM do fragmento de Floresta Ombrófila Mista localizado em São João do Triunfo - PR.

\begin{tabular}{|c|c|}
\hline $\begin{array}{l}\text { FAMÍLIA } \\
\text { ESPÉCIE }\end{array}$ & USOS \\
\hline $\begin{array}{l}\text { Apiaceae } \\
\text { Cyclospermum leptophyllum (Pers.) Sprague }\end{array}$ & Medicinal (ITN) \\
\hline $\begin{array}{l}\text { Bignoniaceae } \\
\text { Macfadyena unguis-cati (L.) Gentry * }\end{array}$ & Medicinal; ornamental \\
\hline $\begin{array}{l}\text { Commelinaceae } \\
\text { Commelina sp }\end{array}$ & Medicinal; ornamental \\
\hline $\begin{array}{l}\text { Dicksoniaceae } \\
\text { Dicksonia sellowiana Hook. * }\end{array}$ & Medicinal; ornamental; fabricação de vasos, palitos, etc \\
\hline $\begin{array}{l}\text { Dryopteridaceae } \\
\text { Polystichum montevidense (Spreng.) Rosenst. }\end{array}$ & Fornecedora de óleo essencial \\
\hline $\begin{array}{l}\text { Lythraceae } \\
\text { Heimia myrtifolia Cham. \& Schltdl. }\end{array}$ & Medicinal \\
\hline $\begin{array}{l}\text { Malvaceae } \\
\text { Pavonia sepium St. Hil. }\end{array}$ & Ornamental \\
\hline $\begin{array}{l}\text { Malvaceae } \\
\text { Abutilon sp }\end{array}$ & Medicinal; ornamental \\
\hline $\begin{array}{l}\text { Marantaceae } \\
\text { Calathea sp }\end{array}$ & Ornamental \\
\hline $\begin{array}{l}\text { Melastomataceae } \\
\text { Leandra australis (Cham.) Cogn. }\end{array}$ & Medicinal \\
\hline $\begin{array}{l}\text { Melastomataceae } \\
\text { Miconia hyemalis A.St.-Hil. \& Naudin }\end{array}$ & Forragem \\
\hline $\begin{array}{l}\text { Mimosaceae } \\
\text { Acacia bonariensis Gill. Ex Hook. et Arn. }\end{array}$ & Medicinal; potencial apícola \\
\hline $\begin{array}{l}\text { Mimosaceae } \\
\text { Calliandra brevipes Benth. }\end{array}$ & Ornamental \\
\hline $\begin{array}{l}\text { Myrtaceae } \\
\text { Myrceugenia ovata (Hook et Arn.) Berg }\end{array}$ & Ornamental \\
\hline $\begin{array}{l}\text { Myrtaceae } \\
\text { Eugenia sp }\end{array}$ & Medicinal; ornamental \\
\hline
\end{tabular}


SANQUETTA, C. R. et al. Inventário de plantas fornecedoras...

\begin{tabular}{ll}
\hline $\begin{array}{l}\text { Piperaceae } \\
\text { Piper xylosteoides (Kunth) Steud. * }\end{array}$ & $\begin{array}{l}\text { Medicinal; fornecedora de óleo essencial; alimentício; } \\
\text { cosmético }\end{array}$ \\
\hline $\begin{array}{l}\text { Pteridaceae } \\
\text { Adiantum raddianum C. Presl * }\end{array}$ & Medicinal; ornamental \\
\hline $\begin{array}{l}\text { Rubiaceae } \\
\text { Coccocypselum lanceolatum (Ruiz \& Pav.) Pers. }\end{array}$ & Medicinal; ornamental \\
\hline $\begin{array}{l}\text { Sapindaceae } \\
\text { Allophylus guaraniticus L. }\end{array}$ & Preparação de bebidas \\
\hline $\begin{array}{l}\text { Solanaceae } \\
\text { Brunfelsia pauciflora (Cham. \& Schltdl.) Benth. }{ }^{*}\end{array}$ & Medicinal; ornamental; fabricação de floral; cosmético \\
\hline $\begin{array}{l}\text { Solanaceae } \\
\text { Cestrum sp }\end{array}$ & Ornamental \\
\hline Tiliaceae & Medicinal \\
\hline Triumfetta semitriloba L.
\end{tabular}

* Espécies não arbóreas com hábito terrestre prioritárias

TABELA 4 - Lista de epífitas potenciais fornecedoras de PFNM do fragmento de Floresta Ombrófila Mista localizado em São João do Triunfo - PR.

\begin{tabular}{ll}
\hline \multicolumn{1}{c}{ ESPÉCIE } & USOS \\
\hline $\begin{array}{l}\text { Bromeliaceae } \\
\text { Billbergia nutans Wendl. }{ }^{*}\end{array}$ & Ornamental \\
\hline $\begin{array}{l}\text { Bromeliaceae } \\
\text { Tillandsia tenuifolia L. }\end{array}$ & Ornamental \\
\hline $\begin{array}{l}\text { Bromeliaceae } \\
\text { Aechmea recurvata (Klotzsch) L.B. Sm. }{ }^{*}\end{array}$ & Medicinal; ornamental \\
\hline $\begin{array}{l}\text { Orchidaceae } \\
\text { Orchidaceae }\end{array}$ & Ornamental \\
\hline $\begin{array}{l}\text { Campylocentrum aromaticum } \text { Barb. Rodr. } \\
\text { Colypodiaceae }\end{array}$ & Ornamental \\
\hline
\end{tabular}

* Epífitas prioritárias

As espécies prioritárias de hábito terrestre raddianum e Brunfelsia pauciflora apresentaram encontram-se presentes dentre os valores mais baixos valores relativamente baixos, com relação às outras de IVI do inventário, sendo que Dicksonia sellowiana espécies do inventário, com 20 indivíduos ha $^{-1}$. Como apresentou maior valor com $9,37 \%$ e Brunfelsia já foi observado anteriormente, as diferenças dos pauciflora apresentou o valor mais baixo, com 0,47\%. parâmetros horizontais entre as espécies podem O xaxim (Dicksonia sellowiana) tem um valor ocorrer devido à biologia da espécie, grau de importante enquanto espécie ornamental e também antropização, fase sucessional da floresta, etc.

como medicinal, porém anos de extrativismo desenfreado provocaram a redução de suas reservas que apresentou maior valor de densidade absoluta foi nas florestas remanescentes (Nascimento et al., Billbergia nutans, com 488 indivíduos ha ${ }^{-1}$. Essa 2001). Já Brunfelsia pauciflora, arbustiva, também espécie apresentou valores relativamente altos, conhecida como manacá-de-cheiro pertence a um quando comparada às epífitas com os maiores valores gênero composto por mais de vinte táxons, com ampla do inventário e esteve presente em todos os estratos distribuição no Brasil (Carvalho et al., 2001) e com dos forófitos avaliados no levantamento. Essa muitos usos potenciais, porém esta especificamente é bromélia, que tem fins ornamentais, tem sido empregada como ornamental (Floridata, 2010).

Todas as espécies com hábito terrestre mas também em outras unidades geográficas dentro destacadas não apresentam valores altos de do Bioma Mata Atlântica (Bonnet et al., 2010).

densidade absoluta, quando comparadas às demais As espécies Aechmea recurvata e espécies do inventário. A espécie que apresentou Campyloneurum phyllitidis encontram-se com valores maior valor foi Piper xylosteoides, com 156 indivíduos de densidade absoluta de 98 e 78 indivíduos ha ${ }^{-1}$, $\mathrm{ha}^{-1}$. Porém, esse valor ainda é baixo quando respectivamente, e estavam presentes em 3 dos comparado Leandra australis, espécie que apresentou estratos avaliados. Os parâmetros horizontais o maior valor de densidade absoluta, com 3.691 referentes à análise fitossociológica das espécies de indivíduos ha $^{-1}$. Essa espécie é citada como de uso hábito terrestre e epifítico fornecedoras de PFNM medicinal e alimentar (Wiest et al., 2009). podem ser verificados nas Tabelas 5 e 6, assim como

A espécie Macfadyena unguis-cati apresentou podem ser verificadas as posições das epífitas, valor de densidade absoluta de 59 indivíduos ha-1. As fornecedoras de PFNM, nas diferentes alturas do demais espécies, Dicksonia sellowiana, Adiantum forófito, na Tabela 7. 
SANQUETTA, C. R. et al. Inventário de plantas fornecedoras...

TABELA 5 - Variáveis da estrutura horizontal das espécies não arbóreas com hábito terrestre fornecedoras de PFNM do fragmento de Floresta Ombrófila Mista localizado em São João do Triunfo - PR.

\begin{tabular}{|c|c|c|c|c|c|c|c|c|}
\hline \multirow[b]{2}{*}{ ESPÉCIE } & $\mathrm{DN} \mathrm{Ab}$ & $\mathrm{DAb}$ & $\mathrm{FR} \mathrm{Ab}$ & DN Rel & D Rel & FR Rel & IVC & $\mathrm{IVI}$ \\
\hline & Ind. ha ${ }^{-1}$ & $\mathrm{~m}^{2} \mathrm{ha}^{-1}$ & $\%$ & $\%$ & $\mathrm{~m}^{2} \mathrm{ha}^{-1}$ & $\%$ & $\begin{array}{c}\% \\
0-200\end{array}$ & $\begin{array}{c}\% \\
0-300\end{array}$ \\
\hline Leandra australis & 3691,41 & 68,46 & 22,66 & 24,02 & 3,25 & 9,21 & 27,27 & 36,47 \\
\hline Polystichum montevidense & 1523,44 & 416,00 & 31,25 & 9,91 & 19,76 & 12,70 & 29,67 & 42,37 \\
\hline Acacia bonariensis & 527,34 & 16,60 & 13,28 & 3,43 & 0,79 & 5,40 & 4,22 & 9,62 \\
\hline Myrceugenia ovata & 273,44 & 62,80 & 6,25 & 1,78 & 2,98 & 2,54 & 4,76 & 7,30 \\
\hline Calathea $s p$ & 234,38 & 15,56 & 4,69 & 1,52 & 0,74 & 1,90 & 2,26 & 4,17 \\
\hline Piper xylosteoides * & 156,25 & 4,44 & 3,13 & 1,02 & 0,21 & 1,27 & 1,23 & 2,50 \\
\hline Allophylus guaraniticus & 136,72 & 2,54 & 3,91 & 0,89 & 0,12 & 1,59 & 1,01 & 2,60 \\
\hline Cestrum sp. & 117,19 & 9,76 & 1,56 & 0,76 & 0,46 & 0,63 & 1,23 & 1,86 \\
\hline Eugenia sp. & 97,66 & 10,56 & 3,13 & 0,64 & 0,50 & 1,27 & 1,14 & 2,41 \\
\hline Abutilon sp. & 78,13 & 2,08 & 2,34 & 0,51 & 0,10 & 0,95 & 0,61 & 1,56 \\
\hline Macfadyena unguis-cati * & 58,59 & 0,84 & 2,34 & 0,38 & 0,04 & 0,95 & 0,42 & 1,37 \\
\hline Pavonia sepium & 58,59 & 7,25 & 1,56 & 0,38 & 0,34 & 0,63 & 0,73 & 1,36 \\
\hline Calliandra brevipes & 58,59 & 11,25 & 0,78 & 0,38 & 0,53 & 0,32 & 0,92 & 1,23 \\
\hline Miconia hyemalis & 39,06 & 0,52 & 1,56 & 0,25 & 0,02 & 0,63 & 0,28 & 0,91 \\
\hline Dicksonia sellowiana * & 19,53 & 187,91 & 0,78 & 0,13 & 8,93 & 0,32 & 9,05 & 9,37 \\
\hline Triumfetta semitriloba. & 19,53 & 0,71 & 0,78 & 0,13 & 0,03 & 0,32 & 0,16 & 0,48 \\
\hline Heimia myrtifolia & 19,53 & 0,68 & 0,78 & 0,13 & 0,03 & 0,32 & 0,16 & 0,48 \\
\hline Adiantum raddianum * & 19,53 & 0,64 & 0,78 & 0,13 & 0,03 & 0,32 & 0,16 & 0,48 \\
\hline Brunfelsia pauciflora * & 19,53 & 0,50 & 0,78 & 0,13 & 0,02 & 0,32 & 0,15 & 0,47 \\
\hline Commelina sp. & 19,53 & 0,35 & 0,78 & 0,13 & 0,02 & 0,32 & 0,14 & 0,46 \\
\hline Cyclospermum leptophyllum & 19,53 & 0,30 & 0,78 & 0,13 & 0,01 & 0,32 & 0,14 & 0,46 \\
\hline Coccocypselum lanceolatum & 19,53 & 0,19 & 0,78 & 0,13 & 0,01 & 0,32 & 0,14 & 0,45 \\
\hline
\end{tabular}

DN: Densidade; D: Dominância absoluta; FR: Freqüência; IVC: Índice de valor de cobertura; IVI: Índice de valor de importância; Ab: Absoluta; Rel: Relativa.

* Espécies não arbóreas com hábito terrestre prioritárias

TABELA 6 - Parâmetros horizontais das epífitas fornecedoras de PFNM do fragmento de Floresta Ombrófila Mista localizado em São João do Triunfo - PR.

\begin{tabular}{lcccc}
\hline \multicolumn{1}{c}{ ESPÉCIE } & DN Ab & FR Ab & DN Rel & FR Rel \\
\cline { 2 - 5 } & Ind. ha ${ }^{-1}$ & $\%$ & $\%$ & $\%$ \\
\hline Billbergia nutans * & 488,28 & 14,84 & 12,02 & 12,50 \\
\hline Tillandsia tenuifolia $^{*}$ Aechmea recurvata * & 253,91 & 7,813 & 6,25 & 6,58 \\
\hline Campyloneurum phyllitidis * $^{*}$ Pleurothallis sonderana & 97,66 & 2,34 & 2,40 & 1,97 \\
\hline Campylocentrum aromaticum & 78,13 & 2,34 & 1,92 & 1,97 \\
\hline
\end{tabular}

DN: Densidade; FR: Freqüência; Ab: Absoluta; Rel: Relativa.

* Epífitas prioritárias

TABELA 7 - Número de indivíduos de epífitas fornecedoras de PFNM localizados nos diferentes estratos do forófito.

\begin{tabular}{lccccc}
\hline & \multicolumn{5}{c}{ Posição no forófito } \\
\cline { 2 - 6 } ESPÉCIE & $>1 \mathrm{~m}$ & $1-2 \mathrm{~m}$ & $2-4 \mathrm{~m}$ & $4-6 \mathrm{~m}$ & $6-8 \mathrm{~m}$ \\
\hline Billbergia nutans * & 10 & 2 & 3 & 6 & 4 \\
\hline Tillandsia tenuifolia $^{*}$ Aechmea recurvata * $^{*}$ & 2 & 4 & 3 & 3 & 1 \\
\hline Campyloneurum phyllitidis * & 3 & 0 & 1 & 0 & 1 \\
\hline Pleurothallis sonderana & 2 & 0 & 1 & 0 & 1 \\
\hline
\end{tabular}

*Epífitas prioritárias

Scientia Agraria, Curitiba, v.11, n.5, p.359-369, Sept./Oct. 2010. 
SANQUETTA, C. R. et al. Inventário de plantas fornecedoras...

Verificou-se através da revisão de literatura que algumas das espécies encontradas como medicinais não apresentam uma comprovação científica, porém seu uso é bem difundido popularmente, apresentando registros de utilização pelas populações indígenas e na medicina caseira. Existe uma quantidade maior de estudos que objetivam avaliar o potencial não madeireiro de algumas espécies arbóreas da Floresta Ombrófila Mista. Das demais espécies (não arbóreas) existem menor quantidade de relatos, evidenciando assim uma necessidade de se desenvolver e incentivar mais pesquisas neste sentido. Ainda é possível encontrar na literatura registros de espécies não arbóreas que não foram levantadas no inventário florestal em questão, porém que ocorrem na Floresta Ombrófila Mista, como a carqueja, que apresenta propriedades medicinais, conforme indicado por Sanquetta \& Mattei (2006), o guaco e a macela, também com propriedades medicinais, comentadas por Blum \& Oliveira (2006).

\section{CONCLUSÕES}

O inventário florestal realizado no presente estudo identificou 134 espécies vegetais, sendo que 72 são fornecedoras de PFNM, ou seja, mais de $53 \%$ das espécies identificadas são fornecedoras de produtos não madeireiros, segundo a literatura.

Foram encontrados no inventário mais de 20 mil indivíduos ha ${ }^{-1}$, sendo $4,3 \%$ de indivíduos arbóreos, $75,6 \%$ de indivíduos não arbóreos de hábito terrestre e $20 \%$ de indivíduos não arbóreos de hábito epifítico.

Dentre os $4,3 \%$ de indivíduos arbóreos encontrados no inventário, concentram-se $62 \%$ das espécies identificadas como fornecedoras de PFNM, o que evidência o potencial das espécies arbóreas comparadas com as espécies não arbóreas.

Esses resultados comparados com outros trabalhos similares validam 0 potencial de fornecimento de PFNM do fragmento de floresta estudado, visto o fornecimento de um número considerável de espécies e produtos florestais não madeireiros, conforme os valores apresentados com relação à quantidade e distribuição espacial das espécies não madeireiras.

\section{REFERÊNCIAS}

1. AGRA, M.F.; FREITAS, P.F.; BARBOSA-FILHO, J.M. Synopsis of the plants known as medicinal and poisonous in Northeast of Brazil. Brazilian Journal of Pharmacognosy, v. 17, n.1, p.114-140, 2007.

2. AMARANTE, C.V.T.; MOTA, C.S.; MEGGUER, C.A.; IDE, G.A. Conservação pós-colheita de pinhões - sementes de Araucaria angustifolia (Bertoloni) Otto Kuntze - armazenados em diferentes temperaturas. Ciência Rural, v. 37, n. 2, p. 346-351, 2007.

3. ARCE, J. E. Florexel - Funções Florestais desenvolvidas para o Microsoft Excel. Centro de Ciências Florestais e da Madeira - CCFM - Universidade Federal do Paraná. Curitiba-PR. Software de distribuição restrita, 2002.

4. AZEVEDO, S.K.S.; SILVA, I.M. Plantas medicinais e de uso religioso comercializadas em mercados e feiras livres no Rio de Janeiro, RJ, Brasil. Acta Botanica Brasiliensis, v. 20, n. 1, p. 85-194, 2006.

5. BACKES, P. \& IRGANG, B. Árvores do sul: Guia de identificação e interesse ecológico: as principais espécies arbóreas sul-brasileiras. 1. ed. Porto Alegre: Instituto Souza Cruz, Clube da Árvore, 2002. 326 p.

6. BALZON, D. R.; SILVA, J.C.L.; SANTOS, A.J. Aspectos mercadológicos de produtos florestais não madeireiros análise retrospectiva. Revista Floresta, v.34, n.3, p.363-371, 2004.

7. BITTENCOURT, S.; DALLA CORTE, A.P.; SANQUETTA, C.R. Estrutura da comunidade de Pteridophyta em uma Floresta Ombrófila Mista, Sul do Paraná, Brasil. Revista Silva Lusitana, v.12, n.2, p.243-254, 2004.

8. BLUM, C. T.; OLIVEIRA, R. de F. Reserva florestal legal no Paraná, alternativas de recuperação e utilização sustentável. Disponível em: <http://www.sobrade.com.br/eventos/2003/seminario/Trabalhos/009.pdf>. Acesso em 11 de dezembro de 2006.

9. BONNET, AL; CURCIO, G.R.; LAVORANTI, O.J.; BARDDAL, M.L.; RODERJAN, M.L. Relações de bromeliáceas epifíticas com fatores ambientais em planícies de inundação do Rio Iguaçu, Paraná, Brasil. Revista Floresta, v.40, n.1, p.193-208, 2010.

10. CARDOSO, J.H. Aroeira, cultura e agricultura: reflexões que embasam a necessidade de uma educação ambiental rural para uma percepção social agroecológica. Pelotas: Empresa Brasileira de Pesquisa Agropecuária, 2008. 23p. (EMBRAPA Documentos, 245).

11. CARVALHO, L.A.F.; COSTA, L.P.H.; DUARTE, A.C. Diversidade taxonômica e distribuição geográfica das solanáceas que ocorrem no Sudeste Brasileiro (Acnistus, Athenaea, Aureliana, Brunfelsia e Cyphomandra). Rodriguesia, v. 52, n. 80, p. 31-45, 2001.

12. CARVALHO, P. E. R. Espécies arbóreas brasileiras, Brasília, DF: Embrapa Informação Tecnológica; Colombo, PR: Embrapa Florestas, v.1, 2003. 1039p.

13. FENNER, R.; BETTI, A.H.; MENTZ, L.A.; RATES, S.M.K. Plantas utilizadas na medicina popular brasileira com potencial atividade antifúngica. Revista Brasileira de Ciências Farmacêuticas, v.42, n.3, p.369-394, 2006.

14. FIUZA, T.S.; REZENDE, M.H.; SABÓIA-MORAIS, S.M.T; BARA, M.T.; TRESVENZOL, L.M.F.; PAULA, J.R Caracterização farmacognóstica das folhas de Eugenia uniflora L. (Myrtaceae). Revista Eletrônica de Farmácia, v.5, n. 2, p. 01-11, 2008.

15. FLORIDATA. Brunfelsia pauciflora. Disponível em <http://www.floridata.com/ref/b/brun_pau.cfm>. Acesso em: $23 / 06 / 2010$

16. FUPEF (Fundação de Pesquisas Florestais do Paraná). Floresta com araucária no Paraná: conservação e diagnóstico dos remanescentes florestais. Brasília: Ministério do Meio Ambiente, 2004. 236p.

17. GAZONI, V.F. Análise fitoquímica e avaliação do efeito anticolinesterásico do extrato e compostos isolados da Rapanea ferruginea. 2009. 84 f. Dissertação (Mestrado em Ciências Farmacêuticas) - Curso de Pós Graduação em Ciências Farmacêuticas - Universidade do Vale do Itajaí, 2009. 
18. GUERRA, J.G.P. de Q.; SANTOS, A.J.; SANQUETTA, C.R.; BITTENCOURT, A.M.; ALMEIDA, A.N. Quantificação e valoração de produtos florestais não-madeireiros. Revista Floresta, v.39, n.2, p.431-439, 2009.

19. INSTITUTO BRASILEIRO DE GEOGRAFIA E ESTATÍSTICA - IBGE. Manual técnico da vegetação brasileira. Rio de Janeiro: Fundação IBGE, 1992. 92p. (Série Manuais Técnicos em Geociências, 1).

20. LORENZI, H. Árvores brasileiras: manual de identificação e cultivo de plantas arbóreas nativas do Brasil. Nova Odessa, SP: Editora Plantarum. v.2, Ed.2, 1998. 352p.

21. LORENZI, H.; MATOS, F. J. A. Plantas medicinais no Brasil: nativas e exóticas. Nova Odessa, SP: Instituto Plantarum, 2002. 512p.

22. MORAES, A. C.; SAURESSIG, D.; GOMES, G.S.; FIGUEIREDO FILHO, A.; DIAS, A.N. Levantamento preliminar de espécies arbóreas potenciais fornecedoras de produtos não madeireiros na Floresta Nacional de Irati-PR. Disponível em:< http://arvoresdeirati.com/artigos/resumo_eaic3.pdf>. Acesso em: 11 de dezembro de 2006.

23. NASCIMENTO, A.R.T.; LONGHI, S.J.; BRENA, D.A. Estrutura e padrões de distribuição espacial de espécies arbóreas em uma amostra de Floresta Ombrófila Mista em Nova Prata, RS. Ciência Florestal, v.11, n.1, p.105-119, 2001.

24. PEDROSO, K.; WATZLAWICK, L.F.; OLIVEIRA, N.K.; VALEIO, A.F.; GOMES, G.S.; SILVESTRE, R. Levantamento de plantas medicinais arbóreas e ocorrência em Floresta Ombrófila Mista. Revista Ambiência, v.3, n.1, p.39-50, 2007.

25. PEGORARO, A; ZILLER, S.R. Valor apícola das espécies vegetais de duas fases sucessionais da Floresta Ombrófila Mista, em União da Vitória, Paraná - Brasil. Boletim de Pesquisa Florestal, n. 47, p. 69-82, 2003.

26. PIZATTO, W. Avaliação biométrica da estrutura e da dinâmica de uma Floresta Ombrófila Mista em São João do Triunfo - PR: 1995 a 1998. 1999. 172 f. Dissertação (Mestrado em Ciências Florestais) - Curso de Pós-Graduação em Engenharia Florestal, Setor de Ciências Agrárias, Universidade Federal do Paraná, Curitiba, 1999.

27. PRADO, A.P. Aspectos autoecológicos e silviculturais de Eugenia involucrata DC. 2009. 118 f. Dissertação (Mestrado em Ciências Florestais) - Curso de Pós-Graduação em Engenharia Florestal, Centro de Ciências Rurais, Universidade Federal de Santa Maria, Santa Maria, 2009.

28. SANQUETTA, C. R.; MATTEI, E. Perspectiva de recuperação e manejo sustentável das florestas de Araucária. Curitiba: Multi-Graphic Gráfica e Editora, 2006. 264 p.

29. SANTOS, A. J. dos; HILDEBRAND, E.; PACHECO, C.H.P.; PIRES, P.T.L.; ROCHADELLI, R. Produtos não madeireiros: conceituação, classificação, valoração e mercados. Revista Floresta, v. 33, n. 2, p. 215-224, 2003

30. STORCK, L.; DALCOL, L.; SANTOS, P.M.; CARVLHO, M.P.; CARDINAL, A.B.B. Precisão experimental em erva-mate (Ilex paraguariensis St. Hil.). Ciência Florestal, v. 12, n. 1, p.159-161, 2002.

31. WICKENS, G. E. Management issues for development of non-timber forest products. Unasylva, v.42, n.165, p.3-8, 1991.

32. WIEST, J.M.; CARVALHO, H.H.; AVANCINI, C.A.M.; GONCCALVES, A.R. Atividade anti-estafilócica em extratos de plantas com indicativo medicinal ou condimentar. Revista Brasileira de Plantas Medicinais, v.11, n.2, p.209-215, 2009.

Recebido em 28/08/2009 Aceito em 09/11/2010 
